\title{
Adoption of Software Testing to School and Colleges (India- Karnataka State)
}

\author{
Praveen P. Badami \\ Lecturer \\ Smt. Kumudben Darbar College of Commerce, \\ Science and management Studies, Vijayapura
}

\begin{abstract}
Software Testing is one of the important filed in software engineering it has a very significance role. A defect free product will be need by customers and at a same time a good technical resources will be accept by industry to test the application with smartness, initial adopting software testing to school and colleges take very important role for preparing students for career in testing and a practical knowledge of people, process and technology[1]. In this paper we take some testing techniques or type of testing that are suitable to school, colleges and under graduate students and analyzed it by adopting some task by writing Manual test cases in Google sheets and revealed $55 \%$ of bug free product However, awareness and training should be needed on practical aspects to faculty members and students if this can be done no doubts a day will be come, a reliable product and reliable Test engineer should exists form school and college with a aim to minimize the burden to IT companies.
\end{abstract}

\section{General Terms}

Software Testing, Manual Testing, Types of testing

\section{Keywords}

Software Testing for Schools, adopting testing

\section{INTRODUCTION}

Information Technology (IT) industry takes very important role in India to develop and solve socio-economic issues everything we use today is a part of software in it from mobile phones, televisions, banks, cars and traffic controls to a range of applications all these application can run without fail with reliability and with all the time, this means a demands on software development and software testing. Testing Organization can put lots of efforts to reduce and deliver bug free product to customer but if the product undergoes different cycles and number of users increasing then there is possible that defects may be undetected[1] On the other hand the developer should know the business logic and process, how the application is used by end-users. Suppose if the application is web- based then there is no control on how someone uses the application with improper hardware and software regardless all this mishandling the product should run correctly but in case of mission critical software there will accept $100 \%$ bug free application. Now days in graduate's level stress will be given on Software Development Life Cycle (SDLC) programming coding and designing even software Testing subject course is mention by some university and that too elective. This creates a big problem to IT Companies because they have to spend lots of time and money to educate graduates on testing Skills. A formal course should be adopted in testing at an earlier stage in school colleges and then Graduates level and at a same time train the teachers and lecturers by conducting workshop short term certification program. This creates a highly talented testing engineer which IT companies expect and need for giving good solution, quality product to customers.

\section{LITERATURE REVIEW}

\subsection{Adopting Software Testing To Schools}

Now a day's high school students from Class V to Class X have adequate basic knowledge in both Hardware and Software. Day to day life they come across tabs, smart phones, games on desktop PC and there are using this application and in fact they acts like a end-users. If we adopt basic Software engineering and then basic Software testing as a syllabus like science and Mathematics this makes gradually they developed testing skills and it began in earlier stage. Table1 shows the suggestions after survey.

\begin{tabular}{|l|l|l|}
\hline Class & Class V to X & Syllabus \\
\hline \multirow{5}{*}{ Subjects } & Science & \multicolumn{1}{|c|}{-} \\
\cline { 2 - 3 } & Mathematics & \multicolumn{1}{|c|}{-} \\
\cline { 2 - 3 } & Software Engg. & $\begin{array}{l}\text { Software,SDLC, } \\
\text { Application Software's, } \\
\text { Project, Product }\end{array}$ \\
\cline { 2 - 3 } & Software Testing & $\begin{array}{l}\text { Testing, Black Box } \\
\text { testing, Functional testing } \\
\text { Game testing, ad-hoc } \\
\text { testing, Defects }\end{array}$ \\
\cline { 2 - 3 } & Practical & $\begin{array}{l}\text { Testing by giving Games } \\
\text { software and KIDS } \\
\text { Software's and basic } \\
\text { knowledge of Bug } \\
\text { Tracking software }\end{array}$ \\
\hline
\end{tabular}

A Survey has been conducted in our high school for Class V to $\mathrm{X}$ students and Teachers with following points in mind

- Choosing 20 students

- Run the application by giving set of test cases

- Types of testing used : Ad hoc testing or monkey testing, smoke testing, Beta testing, Buddy Testing,

- Bug tracking and logging- Defect Bash

- With an aim of breaking an application. 
Similarly Questionnaire for Awareness and Adoption in testing for Teachers is conducted with following points in mind.

- Bio data of the teacher

- Awareness and Adoption in testing for Teachers

An analysis is shown in results section, raw results without critique or analysis. Testing needed the knowledge of application or product so a kid's software is chosen to test the application.

Just we learn from our high school section that kids always asking questions "why"- "This washing machine button is not working" "beep is not coming "setting a timer or about TV remote control, Desktop PC or smart phone this makes the interesting "what" "Why" and how the software works. The software or application may related to drawing, learning kit, or any science and Mathematics related software's, they always go for functional specification. Without knowing about a bug here we survey by take 10 students giving him checklist and test cases[3][4]

\subsection{Adopting Software Testing To Colleges}

If we go for college student PUC I and II (Class XI and Class XII) we learn students in this section have more scenario with different ideas just as they are using in physics or chemistry subjects, there is also an elective subject of computer science with a programming language like $\mathrm{C}, \mathrm{C}++$ and DBMS as a learning syllabus and a practical is only on programming language. There is no stress on Software engineering or software testing, if adopted software engineering and software testing with a practical skills on testing a application with open source testing tools like web page testing or document testing by writing simple test case and find defects may help to enrich their skills on different scenario and these all help to select software testing as a subject in graduate level and career level. Table 2 shows the suggestions after survey.

A Survey has been conducted in our College Section for PUC I to II students and Lecturers with following points in mind

- Choosing 20 students

- Understanding SRS ,CRS

- Writing Test cases on application ( College Product)

- Testing types: Functional, Exploratory testing, Buddy testing, Web site testing

- Defects Management System

Similarly Questionnaire for Awareness and Adoption in testing for Lecturers is conducted with following points in mind.

- $\quad$ Bio data of the Lecturers

- Awareness and Adoption in testing

An analysis is shown in results section, raw results without critique or analysis. Testing needed the knowledge of application or product so a School and College Management Software are used for testing the application, because students have a good DOMAIN knowledge in these applications.

\begin{tabular}{|l|l|l|}
\hline Class & PUC I and II & Syllabus \\
\hline \multirow{1}{*}{ Subjects } & Physics & \multicolumn{1}{|c|}{-} \\
\cline { 2 - 3 } & Chemistry & \multicolumn{1}{|c|}{-} \\
\cline { 2 - 3 } & Biology & \multicolumn{1}{|c|}{ - } \\
\cline { 2 - 3 } & Computer Science & C, C++, DBMS \\
\cline { 2 - 3 } & Software Engg. & $\begin{array}{l}\text { SDLC Models, Software } \\
\text { Design Basics, Design } \\
\text { Tools, Project and } \\
\text { Product, User Interface } \\
\text { Design, Implementation, } \\
\text { Maintenance }\end{array}$ \\
\cline { 2 - 4 } Software Testing & $\begin{array}{l}\text { Validation, Verification, } \\
\text { why need testing, errors, } \\
\text { fault, defects, Quality, } \\
\text { Quality Assurance, testing } \\
\text { Approaches, Black box } \\
\text { testing White Box testing, } \\
\text { testing levels like unit, } \\
\text { Intergation,System, } \\
\text { Functionality testing's }\end{array}$ \\
\cline { 2 - 3 } & Practical & $\begin{array}{l}\text { IDE tools, writing and } \\
\text { execution of manual test } \\
\text { cases using templates, } \\
\text { assigning team work, } \\
\text { reviewing SRS and Defect } \\
\text { tracking tools }\end{array}$ \\
\hline
\end{tabular}

Table 2

\subsection{Adopting Software Testing To Graduates Level}

Graduates level may be Three years or Four Years the education system does not give importance on software testing most of the Universities adopted programming as a subjects like Java, VB.NET and only few of them adopt software testing as elective subject, following below facts are taken place in universities and Graduates level.

- Lab Manual is only on programming and development tools

- $\quad$ Exercise and practical work taken place on coding and programming

- Academic Projects is done without Testing process, complete stress is on coding

- There is no team work, marks is allowed individuals

- There is no real-life scenarios or quality of product about software testing

- There is no communication skills, which should need for every test engineers[1]

These above all makes the students unaware of what's happening in IT industry and what Industry expects and how to develop careers. Simply they end up while doing any courses after competition of their Graduates without getting jobs in industry.

Following things need to adapt to student at Graduates Level

- First need to train Lectures the important of software testing by conducting workshop by industry people.

- Software testing subject should make it mandatory. 
- Practical knowledge on Test Plan and Software Test Life Cycle, Testing tools, Bug tracking tools and testing a product with good manner.

- Knowledge on test matrices and traceability matrix while doing project work

- Communication and soft skills need and short term certificate program and workshop is conducted

These above steps make the students to get easily job in IT Industry without making more efforts on doing courses after competition of Graduate and this only helps to built their careers and totally help industry people. Dr. James Whittaker, Director of Test Engineering at Google, former Microsoft architect, and former professor of

Computer Science at the Florida Institute of Technology has expressed once his belief that the typical few lectures on software testing during a semester-long course is not adequately teaching software testing. $\mathrm{He}$ has said "If universities paid more attention to testing they'd probably find a lot more partnerships with industry and certainly more jobs for their graduates"[5]

Table3 shows the suggestions after survey.

\begin{tabular}{|c|c|c|}
\hline $\begin{array}{l}\text { Graduates } \\
\text { Level } \\
\text { Courses }\end{array}$ & \multicolumn{2}{|c|}{ Software Testing } \\
\hline \multirow{5}{*}{$\mathrm{BSc} / \mathrm{BCA} / \mathrm{BE}$} & Theory & Practical \\
\hline & $\begin{array}{l}\text { STLC Model, SRS, } \\
\text { CRS }\end{array}$ & $\begin{array}{l}\text { Writing Manual } \\
\text { Test Cases, Test } \\
\text { Scenarios, }\end{array}$ \\
\hline & BVA, ECP,V-Model & $\begin{array}{l}\text { Execution of Test } \\
\text { Cases, Traceability } \\
\text { matrix }\end{array}$ \\
\hline & $\begin{array}{l}\text { Test plan, Test cases, } \\
\text { White box testing, } \\
\text { Black box testing, } \\
\text { Defect management, } \\
\text { Organization } \\
\text { Structures, testing } \\
\text { team }\end{array}$ & $\begin{array}{l}\text { Tasks schedule } \\
\text { using Google } \\
\text { Sheet, Open Source } \\
\text { Testing Tools }\end{array}$ \\
\hline & $\begin{array}{l}\text { Testing Types } \\
\text { Integration System } \\
\text { Acceptance } \\
\text { regression } \\
\text { Performance Usability } \\
\text { Accessibility } \\
\text { Automation test }\end{array}$ & $\begin{array}{lr}\text { Bug } & \text { Tracking } \\
\text { Tools, like Bugzilla } \\
\text { and Working on } \\
\text { live r Testing } \\
\text { Projects plus } \\
\text { Interaction through } \\
\text { Seminar }\end{array}$ \\
\hline
\end{tabular}

\section{METHOD AND MATERIALS}

Different types of software testing are exists in industry with real time scenario. We are discussing adoption of testing techniques at different level of education from high school, college to graduates level such a way that students should easily develop their interest in testing the application.

Here the research techniques used for school, college, Graduates levels with methodology and approach adopted for software testing is described below.

\subsection{Research Questions}

What is the level of adoption of software testing by school colleges and graduates levels?

What are the benefits associated with the adoption of software testing by school college and graduates levels?

\subsection{Data Source and Presentation}

Here we have investigates the level of software testing to school, colleges and graduates levels on our group of institutions, the data was well-structured for students and faculty members of high school section, college section( class XI and XII) and Graduates section with different real time testing and questionnaire parts on students and faculty.

For school - Class V to X

- Functional testing

- Beta testing

- Ad-hoc testing

- Exploratory Testing

- Game testing

For college - Class XI to Xll

- Functional testing

- Alpha testing

- Beta testing

- UI and Usability Testing

- Ad-hoc Testing

- Configuration Testing

- Scenario Testing

- Browser compatibility Testing

- Exploratory Testing.

For Graduates -B.Sc./BCA/BCOM/BA/BE

- $\quad$ Regression Testing

- Retesting

- Smoke testing

- End-to-end Testing

- GUI (Graphical User Interface) testing

- Acceptance Testing

- System testing

- Integration testing

- Automated testing- Script based

For Faculty Members

- Bio data of the Lecturers

- Awareness and Adoption in testing

A total of 20 students from Class V to X students, 20 Students of Class XI and XII and 20 Students of Graduates levels were surveyed in each school, colleges and Graduates levels. Using kids software related to Games and Mathematics are used and school and college management for Class X and XI and academic projects for graduates are used to test and analysis of testing skills, an analysis is shown in results section, raw results without critique or analysis.

\section{RESULTS}

The result of survey of Adoption of Software Testing to School, Colleges and Graduates is given below.

Figure-1 , Figure-2 and Figure-3 shows the Awareness and Adoption of Software Testing in School, College and Degree Sections[7] 


\section{Figure -1 Awareness and Adoption of Software Testing in High School Section}

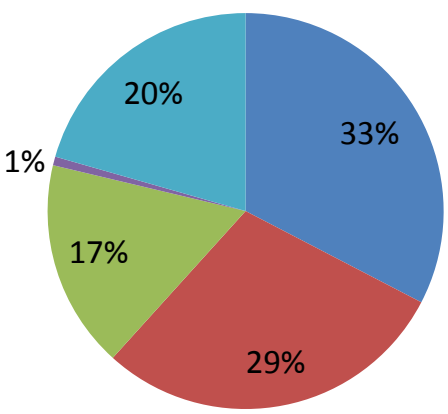

- Software Tools Paint, word,PowerPoint

- Hardware HD,RAM,ROM

Programmimg C Prog

- Software Testing Types, STLC,Game Testing

- Practical Knowledge Tools or Programming

\section{Figure-2 Awareness and Adoption of Software Testing in College Section}

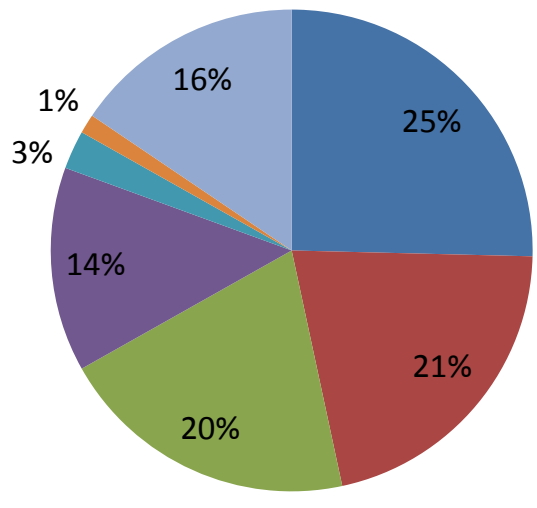

- Software Tools word,PowerPoint,Excel

- Hardware HD,RAM,ROM

- Programmimg Programs, C-

Progms, algorithms,Flowchart

DataBase SQL

Software Engineering SDLC ILifeCycle Models

- Software Testing Types, STLC,Game

Testing

- Practical Knowledge Tools or

Programming

Figure-3 Awareness and Adoption of Software Testing in Graduates Section

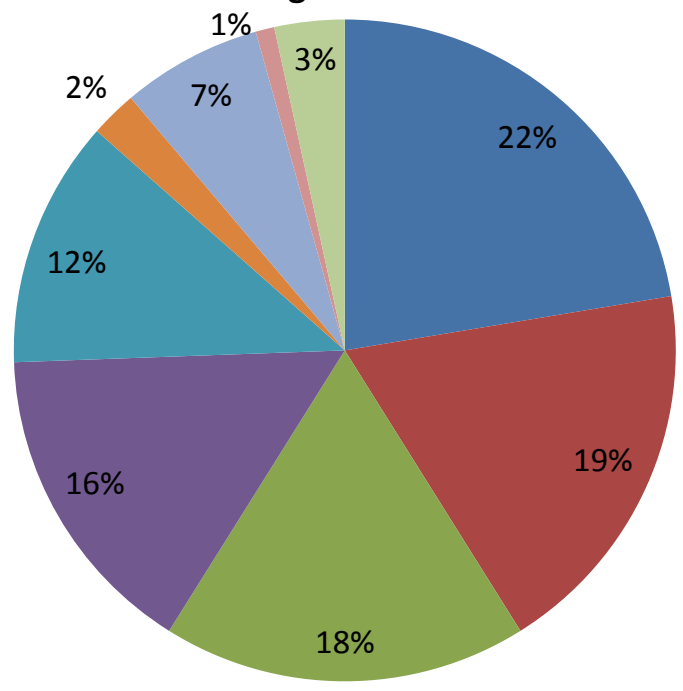

- Software Tools word,PowerPoint,Excel

- Hardware HD,RAM,ROM

- Programmimg C,C++, Java,C Sharp

- IDE Tools Visual Studio, Ecllipse

- DataBase SQL,MYSQL, Oracle

- Software Engineering SDLC LifeCycle Models, Design

Software Testing STLC,Types,Techniques, Tools 
Table - 4

\begin{tabular}{|l|l|}
\hline Testing Metric & Test cases Execution \\
\hline Number of Requirement & 6 \\
\hline Average nu of Test cases Written per requirement & 10 \\
\hline Total No. of test cases written for all requirements & 60 \\
\hline Total No. of test cases Executed & 20 \\
\hline No. of Test cases passed & 10 \\
\hline No. of Test cases failed & 5 \\
\hline No. of Test cases Blocked & 5 \\
\hline No. of Test Cases Not Executed & 40 \\
\hline Total No. of defects identified & 10 \\
\hline Critical Defects count & 5 \\
\hline High defects count & 3 \\
\hline Medium defects Count & 2 \\
\hline Low defects Count & 0 \\
\hline
\end{tabular}

\section{Figure-4 Test Execution Status}

No. of Test cases passed No. of Test cases failed $\quad$ No. of Test cases Blocked

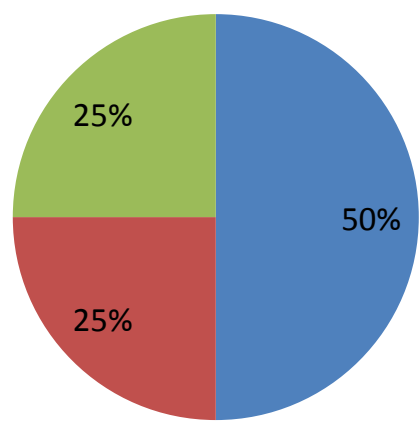

Table-5

\begin{tabular}{|c|c|}
\hline Defects by Priority & \\
\hline Percentage of Critical Defects & $50 \%$ \\
\hline Percentage of High Defects & $30 \%$ \\
\hline Percentage of Medium Defects & $20 \%$ \\
\hline Percentage of Low Defects & $0 \%$ \\
\hline
\end{tabular}

Table -6

\begin{tabular}{|l|r|}
\hline Percentage of Test cases Executed: & $33.30 \%$ \\
\hline Percentage of Test cases not executed: & $66.60 \%$ \\
\hline Percentage of Test cases Passed: & $50 \%$ \\
\hline Percentage of Test cases Failed & $25 \%$ \\
\hline Percentage of Test cases Blocked & $25 \%$ \\
\hline Defect Density & 1.66 \\
\hline Defect Leakage & $55 \%$ \\
\hline
\end{tabular}

Analysis of testing skills for High School, College and Graduates Levels are shown below. Table -4 shows the Test Case Execution Report and Table -5 shows the defects by 
Priority and Table -6 shows the Percentage of test case execution with chart -1 and Chart- 2 .

\section{Chart-1}

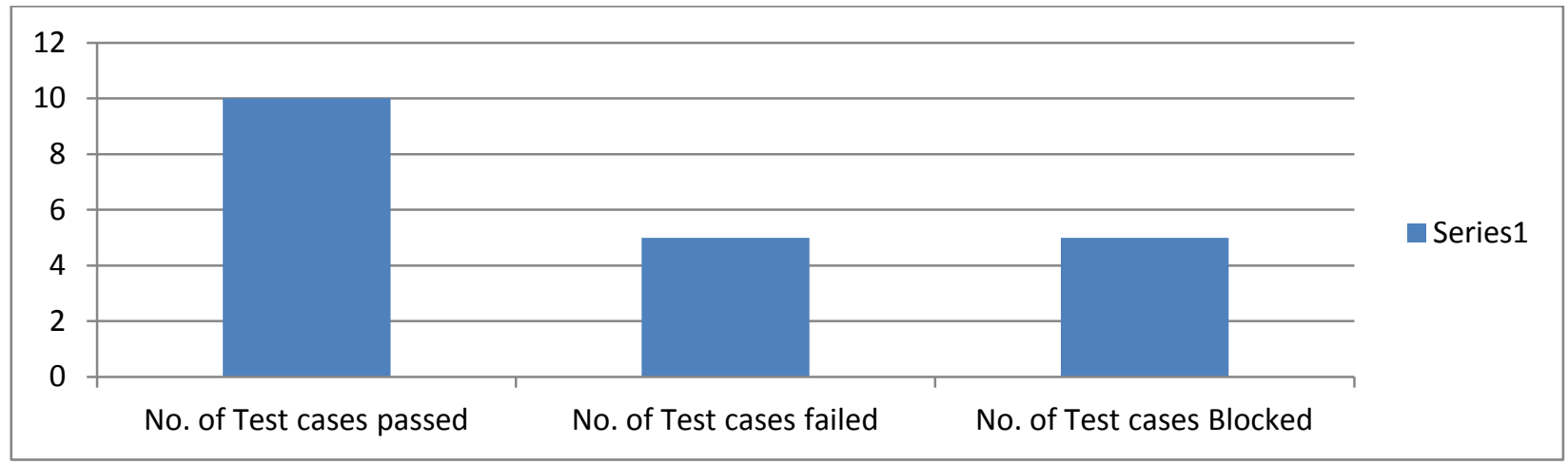

Chart -2
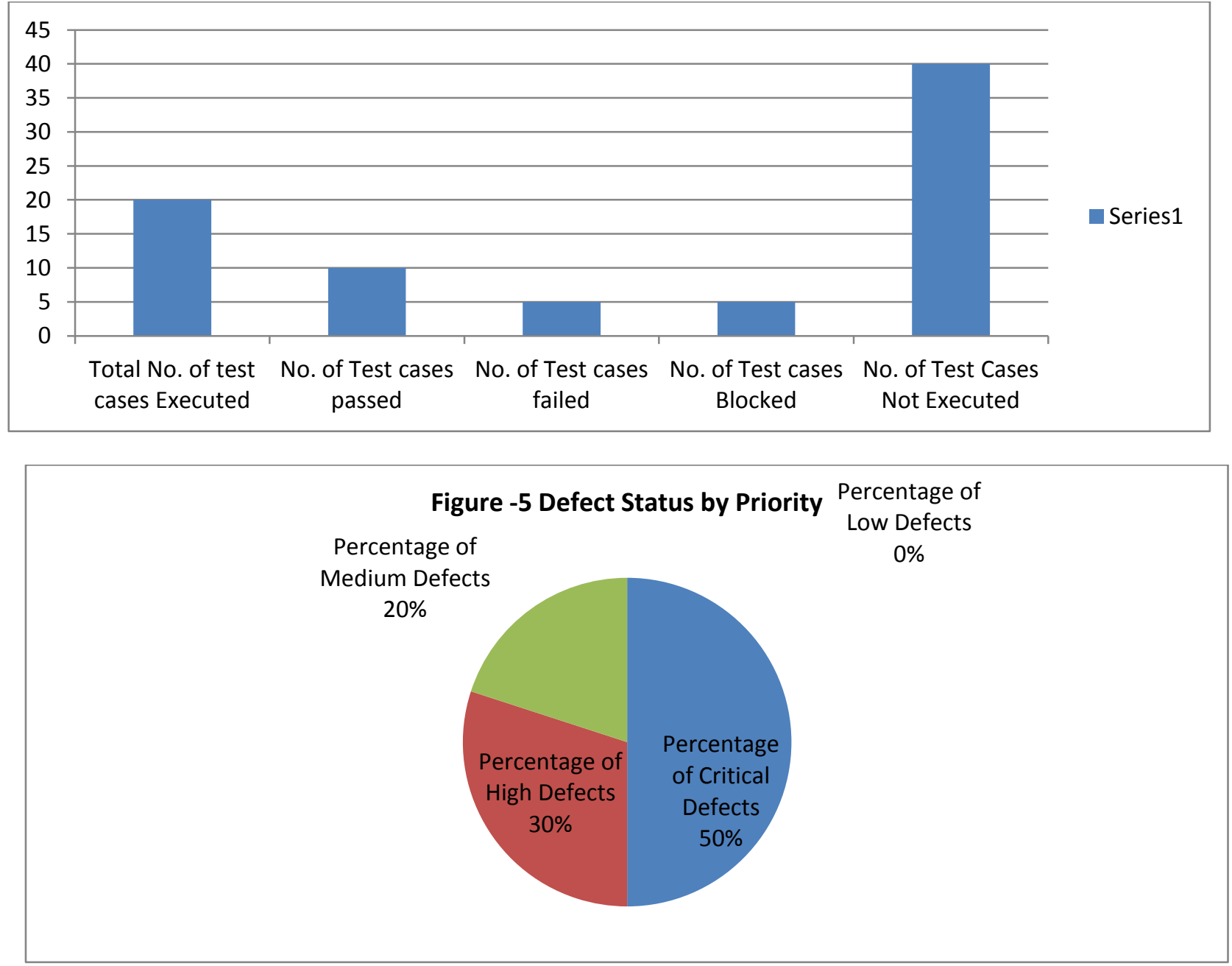

\section{CONCLUSION}

India offers both talent and quality, which make the country a favorable destination to test software for both independent companies and solution providers like Wipro and Infosys.According to the industry experts, India has the potential to corner 70 per cent of the worldwide market of about $\$ 1.82$ billion. The global outsourcing testing market opportunity in the current year has been estimated at $\$ 4.5$ billion, of which, nearly $\$ 3$ billion will be offshored to cheaper destinations [2] Industry observers say the compounded annual growth rate (CAGR) for the independent outsourced testing market is projected at 56 per cent over the next four years. And the CAGR for independent offshore testing is even higher. It stands at 92 per cent. Unfortunately the education from high school to graduates levels only gives 
highest priority to programming language, coding and designing the application. There is no preference on testing, quality of product to customers.[2]Lack of awareness and knowledge of current affairs in IT industry and a understanding between IT INDUSTRY AND ACEDEMIC SYSTEM has been identified as the major barrier to the survival of software testing in education which can be leveraged through the adoption of software testing course at an earlier stage, starting from high school to graduates levels With real time scenarios. Earlier adoption of Software testing can actually help IT industry reduce high expenditures on training the graduates. Based on the results obtained from this research work, the following recommendations are made[8]. The adoption of software testing to school and colleges can help IT companies and academic to:

a) Student should know the importance of software testing without focusing only on programming and coding.

b) Reduce the cost of training fresher's or graduates by industry.

c) Increase in higher productivity and higher quality of testing which results in lower development and support cost.

d) By Knowing practical aspects and real time scenarios and different automated tools, students can choose software testing as their career which in fact a highly skilled test engineers to industry.

\section{FUTURE WORK}

Future research work can investigate on how the constraining factors to the successful adoption of Software testing in school, college and Graduates level can be managed easily without incurring additional overheads. What challenges and issues related to adoption of testing course in earlier stage of school and colleges and impact on IT industry and their quality of the product if they recruit graduates directly[6], EVEN Graduates have learned and trained the testing course in their academic. And how different certification in testing and software testing tools[10] for students and faculty can help and affect the IT industry.

\section{REFERENCES}

[1] Software Testing principles and practices by srinivasan Desikan and Gopalaswamy Ramesh p-314-315

[2] articles.economictimes.indiatimes.com/2004-0909/news/27396260_1_software-testing-testing-marketmicrosoft

[3] Softwaretestingtricks/can-your-kid-beat-you-in-testing

[4] qablog.practitest/2009/04/improve-your-testing-skillstake-a-look-at-your-kids/

[5] "The Emerging role of Software testing in Curricula" by Tara Astigarraga, Eli M. Dow, Christina lara,Richard,maria.

[6] blog.smartbear.com/testing/why-not-train-testers-earlywith- software-testing-degrees/

[7] softwaretestinghelp/software-test-metrics-measurements/

[8] Impact and challenges of cloud compting-adoption on public universities in Nigeria -Oyeleye Akin,Fagbola matthew,Daramola Comfort.

[9] An Environment for Training Computer Science Students on Software testing- Jim Collofello and Kalpana Vehathiri

[10] The Alignment of Software Testing Skills of IS students with Industry Practices - A South African PerpectiveElsje Scott, Alexander zadirov, Sean Feinberg 